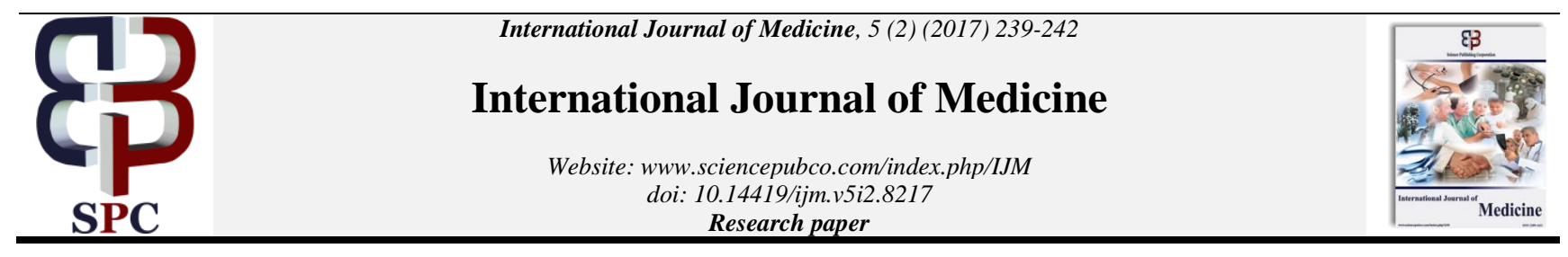

\title{
The effect of long term physical exercises on plasma cortisol levels
}

\author{
W M Manoj Senaka Bandara ${ }^{1 *}$, A J Iresha Sandeepanie Rathnayake ${ }^{1}$, Korotta Gamage Somasiri ${ }^{2}$ \\ ${ }^{1}$ Department of Pre-clinical Sciences, Faculty of Medicine, General Sir John Kotelawala Defence University, \\ Kandawala Road, Ratmalana, Sri Lanka \\ ${ }^{2}$ Department of Physiology, Faculty of Medicine, University of Ruhuna. PO Box 70, Galle, Sri Lanka \\ *Corresponding author E-mail: manojsbw@yahoo.com
}

\begin{abstract}
Regular physical exercises have shown to improve health. Stress can cause great impact on individual's mental health as well as physical health. Plasma cortisol is used as a biomarker to measure stress. This study was carried out to evaluate the effect of long-term physical exercises on cortisol levels in healthy young men. The study was carried out on four study groups; non-exercised control group (NE), exercised for 6 months $(\mathrm{E} 6 \mathrm{M})$, exercised for 18 months $(\mathrm{E} 18 \mathrm{M})$ and exercised for 30 months $(\mathrm{E} 30 \mathrm{M})$. Thirty participants who underwent regular physical exercises for different time periods were included in each exercised group. Thirty controls were also recruited. Plasma cortisol was measured using ELIZA method and compared to the patterns of plasma glucose levels. Plasma cortisol levels of all exercised groups were significantly less than that of control group $(\mathrm{p}<0.05)$. A significant reduction of plasma cortisol level was observed in E6M ( $<<0.001)$ and E18 M ( $<$ 0.001). Plasma cortisol level of E30M was higher than E6M and E18M but less than the control group. Plasma glucose levels followed the same pattern as cortisol. The results of this study suggest that prolong exercises favorably alters the cortisol and glucose levels indicating reduced stress levels in young adults. The study clearly indicates that the prolong exercises have positive effect on the stress marker; plasma cortisol level as well as overall health of an individual.
\end{abstract}

Keywords: Long Term Exercises; Cortisol; Stress; Glucose; Health.

\section{Introduction}

Stress is generally described as a feeling of emotionally overwhelmed, anxious or neglected (Baum, 1990). It is also associated with biochemical, physiological and behavioral changes (Baum, 1990). Stress can cause both psychological health problems as well as physical health. Too much stress causes unhappiness, depression, and anxiety and has become a critical factor in morbidity and mortality (Berger et al. 1988, Lynch, 1975). Many other illnesses such as coronary heart disease, stroke and cancer are associated with stress (Berger et al. 1988, Jenkins, 1976, Maier \& Laudenslager, 1985).

It has been well documented that regular physical exercises improve health (Cornelissen \& Fagard, 2005, Davis et al. 2008, Choudhary \& Binawara 2012, Bandara et al. 2016). In addition to the physiological benefits, a number of psychological benefits are also associated with physical exercises such as reduced depression, anxiety, anger as well as improved mood (Byrne \& Byrne, 1993, Salmon, 2001; Benton, \& Thirlaway, 1992). Physical activities have helped individuals to control stress levels (Hassmen et al. 2000, Nguyen-Michel et al. 2006). The immediate effects of exercise on stress have also been documented (deVries, 1968). The benefits of long-term physical exercises have been reported in diseased populations and in animal models (Blumenthal et al. 2005, Lalanza et al. 2015). However, the conclusions of most of these studies were mainly based on a questionnaire based surveys rather than measuring biochemical markers of stress.

Cortisol is the main glucocorticoid hormone in humans, and it is the prime hormone responsible for the stress response (Lee et al.
2015). Plasma cortisol has been used as a biomarker to measure stress (Kuoppasalmi et al. 1980). The immediate effect of exercise on plasma cortisol levels has also been evaluated (Kuoppasalmi et al, 1980). Nevertheless, the effect of long-term physical exercise on stress measured by cortisol has been overlooked. It has been found that long-term physical exercises help to maintain or increase brain norepinephrine levels (Brown \& Van Huss, 1973, Brown et al. 1979, Dishman et al. 1997). Cortisol is also known to affect plasma glucose levels (Khani \& John, 2001). Hence the aim of this study was to understand the effect of intense long term physical exercises on plasma cortisol levels and to determine if the observed variations correlate to the plasma glucose levels.

\section{Materials and methods}

The participants for this study were comprised of 120 healthy students recruited to the General Sir John Kotelawala Defence University (KDU), Ratmalana, Sri Lanka. The young officer cadets recruited to the KDU undergoes regular intense physical training in addition to their academic work. Ninety cadets were grouped according to the duration of the exercise period they underwent; six months (E6M), eighteen months (E18M), thirty months (E30M). As the control group, civilian students recruited to the KDU who do not participate in any form of regular exercises were taken [non-exercised (NE)]. All of them were randomly selected and consisted of age (18 -22 years), and gender matched four groups with 30 participants in each group. The ethical approval for this study was obtained from the Ethics Review Committee of the KDU, and the study was conducted according to the 
Declaration of Helsinki. Written informed consent was obtained from all participants.

\subsection{Exercise protocol}

The exercise protocol conducted in this study was a supervised, progressive, strength training program, with 45 minute to 2 hour sessions for five days a week which included running, stretching and muscle strengthening exercises. Exercised groups also had to participate for a 45 minute swim per week in addition to the above mentioned exercises.

\subsection{Blood sampling and biochemical determination}

All participants had to undergo 12 hours of overnight fast prior to the experimental analysis. Following morning $5 \mathrm{~mL}$ of venous blood samples were drawn into heparinized tubes. The samples were centrifuged immediately at $1500 \times \mathrm{g}$ for $15 \mathrm{~min}$ to separate plasma. Plasma samples were used to measure cortisol and glucose. Plasma cortisol levels were measured using an ELISA kit (Human, Germany). Glucose concentration was measured by GLUCOSE GOD/PAP (Biolab, France). All the reactions were carried out according to the manufacturer's protocols and colorimetric determination was done at given wave lengths using a spectrophotometer. An interviewer administrated questionnaire was given to the participants to collect information about the participants' sleeping behavior, alcohol usage, smoking habits and medication usage.

\subsection{Statistical analysis}

Statistical analyses were performed using SPSS 20.0 statistical software. Analysis of variance (ANOVA) and a post-hoc test was used to evaluate the mean differences between of exercise groups and NE group. P-value of 0.05 was considered as the cut off for significance.

\section{Results}

Mean plasma cortisol concentrations of different study groups are shown in table 1 and fig.1. Cortisol concentration of the NE group is significantly different from that of the exercised groups and lies near the upper limit of a normal cortisol range of a healthy adult. Both E6M and E18M groups showed significantly lower cortisol values compared to the control group. However E30M group had a higher plasma cortisol level compared to the E6M and E18M groups but was not higher than the control group. Plasma glucose concentrations of each group were correlated with the respective cortisol levels. Both E6M and E18M groups had a lower a plasma glucose levels than the controls group. But in consistent with the trend seen in plasma cortisol levels, the plasma glucose level of E30M group was also higher than E6M and E18M groups and was lower than the control group.

\section{Discussion}

This research was conducted to investigate the effect of long term exercises on stress. The study reveals that the regular physical exercises conducted for long period ( $>6$ months) significantly reduce the plasma cortisol levels which showed a positive correlation with the plasma glucose levels. Blood samples were collected from 30 subjects from each group; however, we had to exclude one subject from each E6M and E30M groups as their blood was clotted at the time of experiment being conducted. Analysis of the questionnaire revealed that none of the subjects of this study had smoked or consumed alcohol or any alcohol containing beverages during 48 hours prior to the time of the collection of blood. In addition, all study subjects have had at least 5 hours sleep in the previous night. No study subject was on any kind of medication or vitamin supplement.

Several attempts have been made to understand the effects of physical exercises on various metabolic parameters. A study conducted by Keselman et al showed that relatively short runningraces can increase insulin and cortisol levels while inducing a reduction in insulin sensitivity (Dmitrašinović et al. 2016). However, Verbickas et al in 2017 showed that the cortisol levels in blood decreased at $24 \mathrm{~h}$ after energy demanding sprint interval exercise and mechanically demanding stretch-shortening cycle exercise (Keselman et al. 2017). Dmitrašinović et al in 2016 found that magnesium supplementation reduces cortisol and IL6 levels in blood levels following strenuous physical exercise (Slimani et al. 2017). In addition, the effect of competition among players during sports activities on stress levels has also been evaluated (Verbickas et al. 2017). Further, this study also discusses how athletes cope up with the stress induced by competition.

The effect of physical exercises on several stress conditions has also been evaluated. An exercise program conducted for two to three times a week results in significantly less depression, anger, cynical distrust, and stress (Hassmen et al. 2000). In addition, these exercises have improved the health and fitness of the individuals who participated in this program (Hassmen et al. 2000). Interestingly it has been shown that students who experienced stress have fewer health issues while they were participating in physical activities (Haugland et al. 2003, Thome \& Espelage, 2004). Nonetheless, the effect of intense long term exercises on stress has not been well studied. Long term exercises slightly improved cognitive function in adults based on Wechsler Memory Scale (WMS) (Hill et al. 1993). Most studies are based on questionnaires and the changes in biochemical parameters of stress responses after exposure to long term exercises have not been evaluated. Hence the present study may provide information to the existing knowledge on the effect of intense long term exercises on psychological status.

Cortisol is a glucocorticoid hormone, secreted by the adrenal cortex in response to physiological or psychological stressors (Hackney, 2006, Wittert et al. 1996). Upon released into the blood, cortisol acts on a variety of peripheral tissues, such as skeletal muscle, adipose tissue, and the liver. In the adipose tissues, it induces the hydrolysis of triglycerides into free fatty acids and glycerol (Hackney, 2006, McMurray \& Hackney, 2000, Viru \& Viru, 2004). It has been found that cortisol increases glycogen breakdown in the liver (Kalamidas \& Kotoulas, 2000). Further, cortisol has shown to stimulate gluconeogenesis in the liver, which provides additional glucose to generate energy (Viru \& Viru, 2004). However, the long-term effects of cortisol on glucose metabolism are yet to be understood.

In our study, we observed lower plasma cortisol and glucose levels in all three exercised groups compared to the non-exercised group. This clearly indicates that regular physical exercises have direct effect on reducing physiological stress levels in young men in an academically stressful environment while improving health. The key causative factors of academic stress have been identified as fear of failing examinations, time management problems, concerns on academic abilities such as grades, etc. (Pozos-Radilloa et al. 2014). The American College Health Association in 2014 stated stress as a key factor that can interfere with academic conductance. Accordingly, academic stress can cause anxiety, depression as well as physical illness in students (Lal, 2014, Deb et al. 2015). We believe that this is a complete scientific evaluation of the effect of intensive long term exercises on plasma cortisol levels. Its correlation with the plasma glucose levels was also evaluated. Results of this study reveal that the long term regular exercises reduce plasma cortisol levels in students in an academically stressful environment with a positive correlation between plasma cortisol and glucose levels. 
Table 1: Means of Plasma Cortisol and Glucose Concentrations Seen in Different Study Groups and P Values of One Way ANOVA.

\begin{tabular}{lllll}
\hline Biochemical parameter & NE & E6M & E18M & E30M \\
\hline Cortisol (ng/ml) & $188.52 \pm 12.44$ & $138.09 \pm 3.84 * *$ & $118.66 \pm 4.87 * *$ & $165.98 \pm 6.88$ \\
$\begin{array}{l}\text { Glucose } \\
(\mathrm{mg} / \mathrm{dl})\end{array}$ & $90.2 \pm 1.7$ & $80.7 \pm 1.7$ & $75 \pm 1.8^{*}$ & 0.000 \\
\hline
\end{tabular}

$\neq$ the data taken from Bandara et al, 2016.

$* \mathrm{P}<0.05$ for the comparison with the control group.

** $\mathrm{P}<0.001$ for the comparison with the control group.

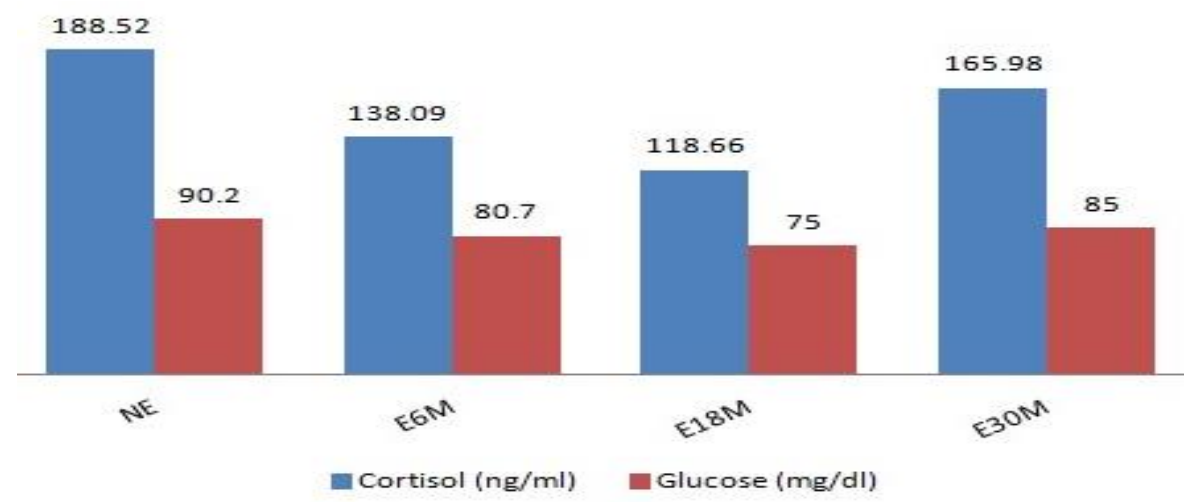

Fig. 1: Plasma Cortisol and Glucose Levels in Different Groups (Non-exercised control group (NE), exercised for 6 months (E6M), exercised for 18 months (E18M) and exercised for 30 months (E30M)).

\section{Conclusions}

Long term intense physical exercises favorably alter the biochemical indicators of mental and physical health.

\section{Acknowledgements}

We thank General Sir John Kotelawala Defence University for financial assistance. The authors would like to thank the administrative and academic staff of the General Sir John Kotelawala Defence University for the support rendered throughout this research.

\section{Conflict of interest}

Authors declare there is no conflict of interest.

\section{References}

[1] Baum A (1990), Stress, Intrusive Imagery and Chronic Distress Health Psychology 9, 653-675. https://doi.org/10.1037/02786133.9.6.653.

[2] Berger BG, Friedmann E, \& Eato M (1988), Comparison of Jogging, the Relaxation Response, and Group Interaction for Stress Reduction. Journal of sport and exercise physiology 10,431-447. https://doi.org/10.1123/jsep.10.4.431.

[3] Lynch JJ (1975), the broken heart: The medical consequences of loneliness. New York: Basic Book.

[4] Jenkins CD (1976), recent evidence supporting psychologic and social risk factors for coronary disease. New England Journal of Medicine 294 ,

987-994. https://doi.org/10.1056/NEJM197604292941806.

[5] Maier SF \& Laudenslager M (1985), Stress and health: Exploring the links. Psychology Today 19, 44-49.

[6] Cornelissen VA \& Fagard RH (2005). Effects of endurance training on blood pressure, blood pressure-regulating mechanisms and cardiovascular risk factors. Hypertension 46, 667-75. https://doi.org/10.1161/01.HYP.0000184225.05629.51.

[7] Davis WJ, Wood DT, Andrews RG, Elkind LM \& Davis WB (2008), Concurrent training enhances athletes' cardiovascular and cardiorespiratory measures. Journal of strength and conditioning research 22 ,

https://doi.org/10.1519/JSC.0b013e3181739f9f.
[8] Choudhary SR \& Binawara BK (2012) Effect of exercise on serum iron, blood haemoglobin and cardiac efficiency. Journal of Postgraduate Medical Institute 26,13-16

[9] Bandara WMMS, Rathnayake AJIS, Basnayake BWMTJ, De Silva MKOK, Edirisinghe D \& Somasiri KG (2016), Long term physical exercises improve cardiometabolic risk factors. Journal of Medical Science \& Technology 5, 34-39.

[10] Byrne A \& Byrne DG (1993), The effect of exercise on depression, anxiety and other mood states: A review. Journal of Psychosomatic Research 37, 565-574. https://doi.org/10.1016/00223999(93)90050-P.

[11] Salmon P (2001), Effects of physical exercise on anxiety, depression, and sensitivity to stress: A unifying theory. Clinical Psychology Review 21, 33-61. https://doi.org/10.1016/S02727358(99)00032-X.

[12] Benton D \& Thirlaway K (1992), Participation in physical activity and cardiovascular fitness have different effects on mental health and mood. Journal of Psychosomatic Research 36, 657-665. https://doi.org/10.1016/0022-3999(92)90055-7.

[13] Hassmen P, Koivula N, Uutela A (2000), Physical Exercise and Psychological Well-Being: A Population Study in Finland. Preventive Medicine 30, 17-25. https://doi.org/10.1006/pmed.1999.0597.

[14] Nguyen-Michel ST, Unger JB, Hamilton J \& Spruijt-Metz D (2006), Associations between physical activity and perceived stress/hassles in college students. Stress and health 22, 179-188. https://doi.org/10.1002/smi.1094.

[15] deVries HA (1968). Immediate and long-term effects of exercise upon resting muscle action potential level. Journal of Sports Medicine and Physical Fitness 8, 1-11.

[16] Blumenthal JA, Sherwood A, Babyak MA, Watkins LL, Waugh R, Georgiades A, Bacon SL, Hayano J, Coleman RE \& Hinderliter A (2005), Effects of exercise and stress management training on markers of cardiovascular risk in patients with ischemic heart disease. The Journal of the American Medical Association 293, 16261634. https://doi.org/10.1001/jama.293.13.1626.

[17] Lalanza JF, Sanchez-Roige S, Cigarroa I, Gagliano H, Fuentes S, Armario A, Capdevila L \& Escorihuela RM (2015), Long-term moderate treadmill exercise promotes stress-coping strategies in male and female rats. Scientific reports, 5-16166. https://doi.org/10.1038/srep16166.

[18] Lee DY, Kim E \& Choi MH (2015), Technical and clinical aspects of cortisol as a biochemical marker of chronic stress. BMB Reports 48, 209-216. https://doi.org/10.5483/BMBRep.2015.48.4.275.

[19] Kuoppasalmi K, Näveri H, Härkönen M \& Adlercreutz H (1980), Plasma cortisol, androstenedione, testosterone and luteinizing hormone in running exercise of different intensities, Scandinavian Journal of Clinical Laboratory Investigation 40, 403-409. https://doi.org/10.3109/00365518009101862.

[20] Brown BS \& Van Huss W (1973). Exercise and rat brain catecholamines. Journal of Applied Physiology, 34,664-669. 
[21] Brown BS, Payne T, Kim C, Moore G, Krebs P \& Martin W (1979), chronic response of rat brain norepinephrine and serotonin levels to endurance training. Journal of applied physiology 46, 19-23.

[22] Dishman RK, Renner KJ, Youngstedt SD, Reigle TG, Bunnell BN, Burke KA, Yoo HS, Mougey EH \& Meyerhof JL (1997), Activity wheel running reduces escape latency and alters brain monoamine levels after footshock. Brain Research Bulletin 42, 399-406. https://doi.org/10.1016/S0361-9230(96)00329-2.

[23] Khani S \& John A (2001). Cortisol increases gluconeogenesis in humans: its role in the metabolic syndrome. Clinical Science 101,739-747. https://doi.org/10.1042/cs1010739.

[24] Dmitrašinović G, Pešić V, Stanić D, Plećaš-Solarović B, Dajak M \& Ignjatović S (2016), ACTH, Cortisol and IL-6 Levels in Athletes following Magnesium Supplementation. Journal of Medical Biochemistry 35, 375-384. https://doi.org/10.1515/jomb-2016-0021.

[25] Keselman B, Vergara M, Nyberg S \& Nystrom FH (2017), A randomized cross-over study of the acute effects of running $5 \mathrm{~km}$ on glucose, insulin, metabolic rate, cortisol and Troponin T. PLoS One, 16;12(6):e0179401. doi:10.1371/journal.pone. 0179401.

[26] Slimani M, Cheour F, Moalla W \& Baker JS (2017). Hormonal responses to a rugby match: a brief review. The Journal of Sports Medicine and Physical Fitness, doi: 10.23736/S00224707.17.07187-0.

[27] Verbickas V, Baranauskiene N, Eimantas N, Kamandulis S, Rutkauskas S, Satkunskiene D, Sadauskas S, Brazaitis M \& Skurvydas A (2017), Effect of sprint cycling and stretch-shortening cycle exercises on the neuromuscular, immune and stress indicators in young men. Journal of Physiology and Pharmacology 68,125-132.

[28] Haugland S, Wold B \& Torsheim T (2003), relieving the pressure? The role of physical activity in the relationship between schoolrelated stress and adolescent health complaints. Research Quarterly for Exercise and Sport 74, 127-135. https://doi.org/10.1080/02701367.2003.10609074.

[29] Thome J \& Espelage DL (2004), Relations among exercise, coping, disordered eating, and psychological health among college students. Eating Behaviors 5, 337-351. https://doi.org/10.1016/j.eatbeh.2004.04.002.

[30] Hill RD, Storandt M \& Malley M (1993), The Impact of Long-term Exercise Training on Psychological Function in Older Adults. $\begin{array}{llll}\text { Journal of } & \text { Gerontology } & \text { 48, } & \text { 12-P7. }\end{array}$ https://doi.org/10.1093/geronj/48.1.P12.

[31] Hackney AC (2006), Stress and the neuroendocrine system: the role of exercise as a stressor and modifier of stress. Expert Review of Endocrinology \& Metabolism 1, 783-92. https://doi.org/10.1586/17446651.1.6.783.

[32] Wittert G, Livesey JH, Espiner EA \& Donald RA (1996). Adaptation of the hypothalamopituitary adrenal axis to chronic exercise stress in humans. Medicine and Science in Sports and Exercise 28, 1015-1019. https://doi.org/10.1097/00005768-199608000-00011.

[33] McMurray RG \& Hackney AC (2000), Endocrine responses to exercise and training. Exercise and sport science, Philadelphia, Lippincott Williams \& Wilkins. 135-61.

[34] Lal K (2014), Academic stress among adolescent in relation to intelligence and demographic factors. American International Journal of Research in Humanities, Arts and Social Sciences, 123-129.

[35] Deb S, Strodl E \& Sun J (2015), Academic Stress, Parental Pressure, Anxiety and Mental Health among Indian High School Students. International Journal of Psychology and Behavioral Sciences 5, 26 34. 